\title{
Dying and living with learning disability: will health checks for adults improve their quality of life?
}

We know that for people with learning disability, this is a life-long condition, and also that it is not associated with long life. Adults with learning disability (intellectual disabilities), have the triad of impaired intelligence, reduced ability to cope independently (impaired social functioning), with both starting before adulthood and resulting in a lasting effect on development. An article in this Journal by Tuffrey-Wijne and colleagues explores in depth, mainly by participant observation, the experiences and needs of 13 patients who were terminally ill. ${ }^{1}$ In at least 10 of the patients the diagnosis of cancer was delayed. Better access to regular cancer screening programmes has the potential to reduce the incidence of late diagnosis in this group; people with learning disability often fail to attend offered screening services, such as mammography and cervical cytology.

This study ${ }^{1}$ highlights the need for GPs to engage proactively in supporting patients and their carers, when this diagnosis is made. This will require skills in and knowledge of communication, capacity, and consent issues. The authors comment that sometimes assumptions were being made wrongly by clinicians, that the carers, whether paid or family, actually knew the understanding and wishes of the patient when the diagnosis of cancer or care arrangements were being discussed. They recommend that where there are cognitive and communication difficulties, and where the wishes and feelings of the patient cannot be gauged with certainty, rather than informally and unquestioningly accepting statements of carers, patients in this situation may benefit from assessment of their mental capacity and a 'best interest' meeting with probable involvement of the local specialist palliative care team. As with other aspects of the care of people with learning disability, communication difficulties may exist, whether information passes directly between doctor and patient, or via a carer, which may mean that diagnosis and treatment are less satisfactory than might otherwise be expected.
How can primary care offer improved qualities of general health care to adults with learning disability? An RCGP working party in 1990 recommended health checks. ${ }^{2}$ The Department of Health sent a series of recommendations, including checks for people with learning disabilities to all GPs in 1999. ${ }^{3}$ The white paper Valuing People ${ }^{4}$ inferred that primary care was the segment of the health service expected to drive forward care for this vulnerable group. It is since the independent inquiry following Death by Indifference ${ }^{5}$ that the Department of Health has made resources available in England. Sir Jonathan Michael's Report Healthcare for All published in $2008^{6}$ recommends the introduction of an annual health check for people with moderate and severe learning disability and stresses the need to make 'reasonable adjustment' for the needs of those with learning disability. This report has now been followed by the publication of new clinical directed enhanced services (DES) guidance for the GMS contract 2008/09, including appendix 3 on learning disabilities, in which practices will be expected to provide an annual health check for their adult patients with learning disabilities. ${ }^{7}$

The introduction of regular structured health checks offers patients with learning disability an extra route of joining mainstream general practice with a higher profile and priority than before. The introduction of child health surveillance clinics in the 1970-1980s highlighted to practices the opportunities of regular systematic care of a population of young patients, and led to increased attention to the needs of the under 5's in practices. For many young patients with significant learning disability, arrangements for developmental monitoring and regular review have often continued through adolescence up to the age of 18 years. However, past this age, up until recently, there has not usually been regular follow-on surveillance, although the associated clinical conditions are likely to remain much the same as when the patient was growing up. It has been shown that comprehensive health checks in adults with learning disability, done correctly, identify hidden morbidity ${ }^{8}$ and could double the number of their health needs addressed, compared with standard GP care.9,10 Those patients with moderate, severe and profound learning disabilities are known to have over twice the number of clinical conditions found in their non- disabled peers. ${ }^{11}$ In a study last year the level of new need revealed by repeated checks, even at the shortest interval (mean 14 months), was as high as that at initial check, which suggests the optimum interval between checks may well be 1 year. Serial health checking led to nearly doubling the health promotion actions in this group, while the rate of primary care consultations between checks did not fall. ${ }^{12}$

Many GPs working with their practice nurses are now offering annual health checks for their patients with learning disabilities. They use Quality Outcomes Framework (QOF) registers of their patients with learning disability, and some practice administrators have set up call and recall systems, and are working out how to reduce non attenders to a minimum while maintaining confidentiality, respecting selfdetermination, and working together with the local services offered by the learning disability teams. Primary care trusts (PCTs) have the responsibility of checking the practice registers against the 'local register,' and good congruence is possible where practices and local community learning disability teams have agreed definitions and regularly update their registers, concentrating on those with moderate, severe, and profound learning disability. However, the personal experience of one of the authors and of a recent publication in this Journal indicates that this may be more difficult than it would appear because the community registers produced by a combination of social services and health statistics and practice registers using electronic templates may not identify quite the same populations. ${ }^{13}$ 
Although we are familiar with 'well person' checks it is useful to be aware of how checking the learning disabled population varies considerably from this. For example, about a quarter of all patients with learning disability will have Down's Syndrome with syndrome-associated clinical conditions that will need specific checking; ${ }^{14,15}$ a further quarter of patients are likely to have active epilepsy. ${ }^{16} \mathrm{~A}$ majority of patients previously in hospitals and other institutions are likely to have had Helicobacter pylori infection and reflux, and gastrointestinal malignancy is also common. ${ }^{17}$ Most lifestyle/health promotion issues, in particular around weight, diet, and exercise can be managed along standard lines, however, smoking and addiction to alcohol and other drugs of dependence are less common. Known comorbidities need checking and the discipline of a structured check will help to avoid diagnostic overshadowing. ${ }^{18}$ Improved care of conditions that are listed QOF clinical indicators, in particular epilepsy, diabetes, and thyroid conditions, should follow. Questionnaires related to current health concerns completed by the patient and carers prior to the health check would also address the patients agenda. From the point of view of patients, many clinical needs for them centre around disordered physiological function; for example, hearing, vision, sleep, eating, obesity, digestion, continence, constipation, and mobility.

To ensure patients obtain real benefit, and that this is an effective use of resources, rather than a box-ticking exercise, identified clinical needs will need to be shown to have been met. A recent Welsh Study of health checks on patients with learning disabilities has shown a first time $9 \%$ pick-up rate for serious new morbidity. ${ }^{8}$ For the actual check, the Welsh Health Check $^{19}$ (which is very comprehensive) or a locally agreed protocol based on this is recommended in the DES. These structured health checks should include review of physical and mental health, medication, and coordination of services. The check should result in a health action plan which the patient, clinicians, and carers can work together to implement.

Some areas where training is said to be required are already covered in the nMRCGP curriculum (Section 14, Care of People with Learning Disabilities). ${ }^{20}$
Practices can also access much useful information at several websites..$^{21,22}$ For practising clinicians 'learning by doing' health checks is a good way of improving skills. In large practices mutual exchange of relevant practical information at the surgery with participation from both the primary care team and local specialist community team has much to recommend it. Alternatively, postgraduate educators may wish to incorporate training in GP sessions with representatives of the specialist local community learning disability teams, along with self-advocates invited to do presentations. For practices in rural communities in particular, e-learning could be a valuable resource. Building on the skills developed and the experience gained at checks year on year, improving care should be being offered to patients with learning disability.

As the health of the nation improves so the number of adults with learning disability including those surviving into old age, is increasing. ${ }^{23}$ It would appear that the primary responsibility for their care is falling increasingly to general practice. It may well be that, as with all ageing populations there may be more cancer cases. It is possible that this vulnerable group of patients, who have difficulties accessing health care, could enjoy better health with earlier diagnosis of several remediable conditions, including some cancers, if the new $\mathrm{DES}^{7}$ is effectively implemented by GPs, working with their nursing colleagues.

\section{Graham Martin,}

Retired GP, Wolvey, nr Hinckley.

\section{Peter Lindsay,}

GP Principal, The Thakur Practice, Leeds.

\section{Provenance}

Freely submitted; peer reviewed.

\section{REFERENCES}

1. Tuffrey-Wijne I, Bernal J, Hubert J, et al. People with learning disabilities who have cancer: an ethnographic study. Br J Gen Pract 2009; 59: 503-509.

2. Royal College of General Practitioners. Primary care for people with a mental handicap. RCGP Occasional paper 47. London: RCGP, 1990.

3. Department of Health. Once a day one or more people with learning disabilities are likely to be in contact with your primary healthcare team: how can you help them? http://www.dh.gov.uk/en/Publicationsandstatistics/Publicati ons/PublicationsPolicyAndGuidance/DH_4006868 (accessed 5 Jun 2009).

4 Department of Health. Valuing People: A new strategy for learning disability for the 21st century.

http://www.dh.gov.uk/en/Publicationsandstatistics/Publicati
ons/PublicationsPolicyAndGuidance/DH_4009153 (accessed 5 Jun 2009).

5. Mencap. Death by Indifference. Mencap, 2007. http://www.mencap.org.uk/case.asp?id=52\&menuId=53 (accessed 5 Jun 2009).

6. Michael, Sir J. Healthcare for All. Report of the independent inquiry into access to healthcare for people with learning disabilities.

http://www.dh.gov.uk/en/Publicationsandstatistics/Publicati ons/PublicationsPolicyAndGuidance/DH_099255 (accessed 5 Jun 2009).

7 NHS Employers. Clinical DES guidance for GMS contract 2008/9. http://www.nhsemployers.org/Aboutus/ Publications/Pages/Guidance-GMS-contract-200809.aspx (accessed 5 Jun 2009).

8. Baxter H, Lowe K, Houston $\mathrm{H}$, et al. Previously unidentified morbidity in patients with intellectual disability. $\mathrm{Br} \mathrm{J} \mathrm{Gen}$ Pract 2006; 56: 93-98.

9. Cooper, SA, Morrison J, Melville C et al. Improving the health of people with intellectual disabilities: outcomes of a health screening programme after 1 year. J Intellect Disabil Res 2006; 50(9): 667-677.

10. Lennox, N, Bain C, Rey-Conde T et al. Effects of a comprehensive health assessment programme for Australian adults with intellectual disability: a cluster randomized trial. Int J Epidemiol 2007. 36(1): 139-146.

11 Van Schrojenstein Lantman-De Valk HM, Metsemakers JF, Haveman MJ, Crebolder HF. Health problems in people with intellectual disability in general practice. Fam Pract 2000; 17: 405-407.

12 Felce D, Baxter H, Lowe K, et al. The impact of repeated health checks for adults with intellectual disabilities. J Appl Res in Intell Disab 2008; 21: 585-596.

13. Allgar V, Mir G, Evans J et al. Estimated prevalence of people with learning disabilities: template for general practice. Br J Gen Pract 2008; 58: 423-428.

14. Henderson A, Lynch SA, Wilkinson S, et al. Adults with Down's Syndrome: the prevalence of complications and health care in the community. Br J Gen Pract 2007; 57: 50-55.

15. Roizen NJ, Patterson D. Downs Syndrome. The Lancet 2003 361:1281-1289.

16 Cooper SA (chair). The health needs assessment report; people with learning disabilities in Scotland. Edinburgh, 2004.

17. Scheepers M, Duff M, Baddeley P, et al. Helicobacter pylori and the learning disabled Br J Gen Pract 2000; 50: 813-814.

18. RCGP Health Inequalities Standing Group. Hard lives: improving the health of people with multiple problems. London: Royal College of General Practitioners, 2003.

19. Royal College of General Practitioners. Cardiff health check for people with a learning disability. http://www.rcgp.org.uk/PDF/clinical_Welsh_Health_Check _newA.pdf (accessed 5 Jun 2009).

20. Royal College of General Practitioners. Royal College of General Practitioners curriculum statement 14. Care of people with learning disabilities. http://www.rcgpcurriculum.org.uk/PDF/cur_14_Learning_disabilities.pdf (accessed 5 Jun 2009).

21. St George's University of London. Learning about intellectual disabilities and health. http://www.intellectualdisability.info (accessed 5 Jun 2009).

22. Easy health.org.uk. http://www.easyhealth.org.uk (accessed 5 Jun 2009).

23. Cooper, SA Melville C, Morrison J. People with intellectual disabilities. Their health needs differ and need to be recognised and met. BMJ 2004; 329: 414-415.

DOI: 10.3399/bjgp09X453503

ADDRESS FOR CORRESPONDENCE

Graham Martin

Cragside, Wolvey, nr Hinckley, LE10 3LA

E-mail graham@ghbmartin.co.uk 